\title{
DETERMINAÇÃO DA ÁREA FOLIAR EM VIDEIRA CULTIVAR NIAGARA ROSADA (1)
}

\author{
MÁRIO JOSÉ PEDRO JÚNIOR $(2,5)$, IVAN JOSÉ ANTUNES RIBEIRO $(3,5)$ \\ e FERNANDO PICARELLI MARTINS $(4,5)$
}

\section{RESUMO}

Foi estudada a relação entre a área foliar (AF) e a largura da folha (L) em videira do cultivar Niagara Rosada. A área foliar pode ser estimada pelo uso de um coeficiente que corrige a área do círculo, considerando seu diâmetro igual à largura da folha, mediante a fórmula: $\mathrm{AF}=0,85 \pi(\mathrm{L} / 2)^{2}$.

Termos de indexação: área foliar; videira; Niagara Rosada.

\section{INTRODUÇÃO}

A determinação da área foliar das plantas é de interesse em diferentes setores da pesquisa agronômica. No caso da epifitiologia é de fundamental importância que as técnicas de estimativa da área foliar do hospedeiro sejam simples, răpidas e, principalmente, não destrutivas.

\footnotetext{
(1) Recebido para publicaçāo em 12 de agosto de 1985. (SP).

(2) Seção de Climatologia Agrícola, Instituto Agronómico (IAC), Caixa Postal 28, 13001 Campinas

(3) Seção de Microbiologia FitotEcnica, IAC.

(4) Estaçāo Experimental de Jundiai, IAC.

(5) Bolsista do CNPq.
} 
Vários métodos têm sido usados para medida da superficie foliar, utilizando-se medidores eletrônicos e técnicas de planimetria (KVET \& MARSHALL, 1971). Devido ao formato irregular das bordas das folhas da videira, torna-se dificil o emprego de planimetros, e como os medidores eletrônicos são importados e, geralmente, onerosos, a estimativa da área foliar através de medições simples é desejável.

No caso da videira, a área foliar e suas relações matemáticas com largura e comprimento das folhas e nervuras, têm sido estudadas, geralmente, para fins de ampelografia. CARBONEAU (1976), discutindo os princípios e métodos da medida da superficie foliar do gênero Vitis, obteve estimativas com $5 \%$ de erro, utilizando medições da soma do comprimento das duas maiores nervuras laterais. MANIVEL \& WEAVER (1974) correlacionaram, em Vitis vinifera, a área foliar com o comprimento e largura da folha e comprimento do peciolo, obtendo curvas de segundo grau para a largura. ARORA \& CHANANA (1975), na İndia, observaram que, para dez cultivares diferentes, a área foliar estava relacionada com seu comprimento e largura. MAKHIJA et alii (1980) observaram que a área foliar podia ser estimada acuradamente, sem ter que destacar as folhas da videira (método não destrutivo), usando determinações do comprimento máximo e da largura da folha.

Com base nos estudos anteriores, objetivou-se nesse trabalho o desenvolvimento de uma técnica que permitisse, através de medições da largura, a determinação da área das folhas de videira do cultivar Niagara Rosada, o mais importante para o Estado de São Paulo.

\section{MATERIAL E MÉTODOS}

As folhas analisadas foram coletadas na Estação Experimental de Jundiai em 1983 e 1984, em lote de videiras do cultivar Niagara Rosada, plantadas em 1974. As 220 folhas de diferentes idades e tamanhos foram desenhadas em papel milimetrado, onde foram feitas determinações da área foliar, através de planimetria, bem como medições da largura da parte média da folha.

A área do círculo foi utilizada pela sua similaridade com as folhas da videira (Figura 1), sendo a área foliar (AF) estimada de acordo com:

$$
\mathrm{AF}=\mathrm{C} \cdot \pi \cdot\left(\frac{\mathrm{L}}{2}\right)^{2}
$$

onde $\mathrm{L}$ é a largura da folha e $\mathrm{C}$ um coeficiente de ajuste, determinado mediante regressão linear.

\section{RESULTADOS E DISCUSSĀO}

Os valores obtidos referentes à largura das folhas, bem como os de área foliar, encontram-se na figura $₹$ a curva que melhor se adaptou foi a polino- 
mial de $2^{0}$ grau, semelhante aos resultados apresentados por MANIVEL \& WEAVER (1974), com um coeficiente de determinação $\left(R^{2}\right)$ de 0,98 .

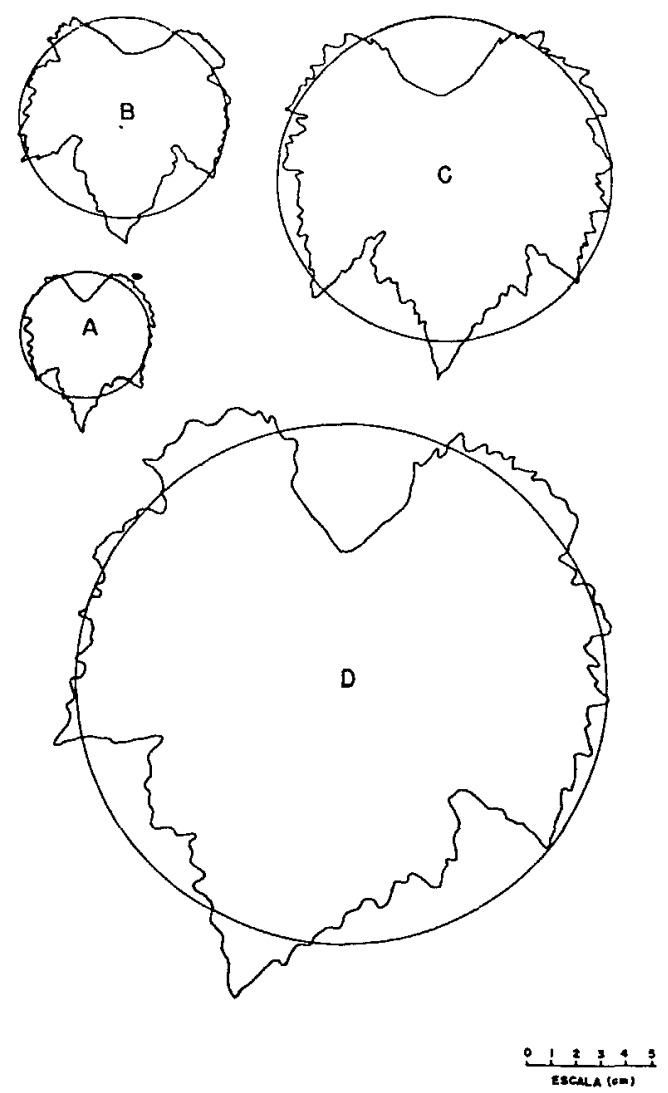

FIGURA 1. Similaridade entre o círculo e folhas de diferentes tamanhos em videira, cv. Niagara Rosada

Posteriormente, os valores da largura das folhas foram transformados em áreas de um círculo, como explicado com relação à figura 1, sendo entāo feita a correlação entre a área foliar medida (AFM) e a área do círculo (AC), obtida através da largura da folha, resultando a equaçāo:

$$
\mathrm{AFM}=3,68+0,83 \mathrm{AC}
$$

com um coeficiente de determinação $\left(R^{2}\right)$ de 0,98 , sendo o erro-padrão da estimativa de $12,2 \mathrm{~cm}^{2}$. 


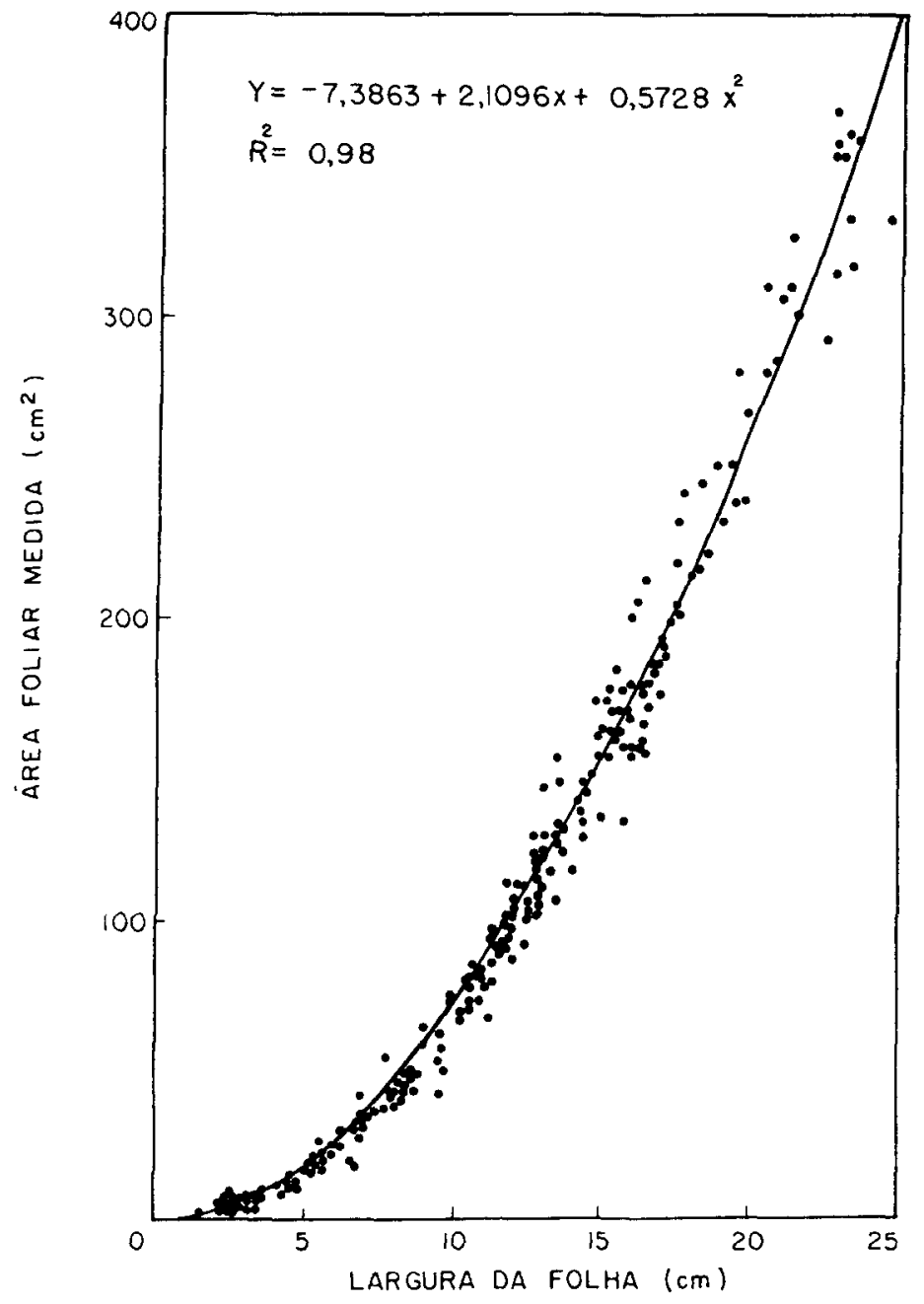

FIGURA 2. Relação entre área foliar e largura da folha em videira, cv. Niagara Rosada.

A equação acima sugeriu a utilização de uma simplificação, ou seja, de um coeficiente apenas $(0,85)$ para corrigir a área do círculo, para estimativa da área foliar.

$$
A F=0,85 \pi\left(\frac{L}{2}\right)^{2}
$$


A comparação entre os valores medidos da área foliar (AFM) e estimados (AF) através da equação (3) são mostrados na figura 3. A equação de regressão obtida foi:

$$
\mathrm{AF}=0,82+0,99 \mathrm{AFM}
$$

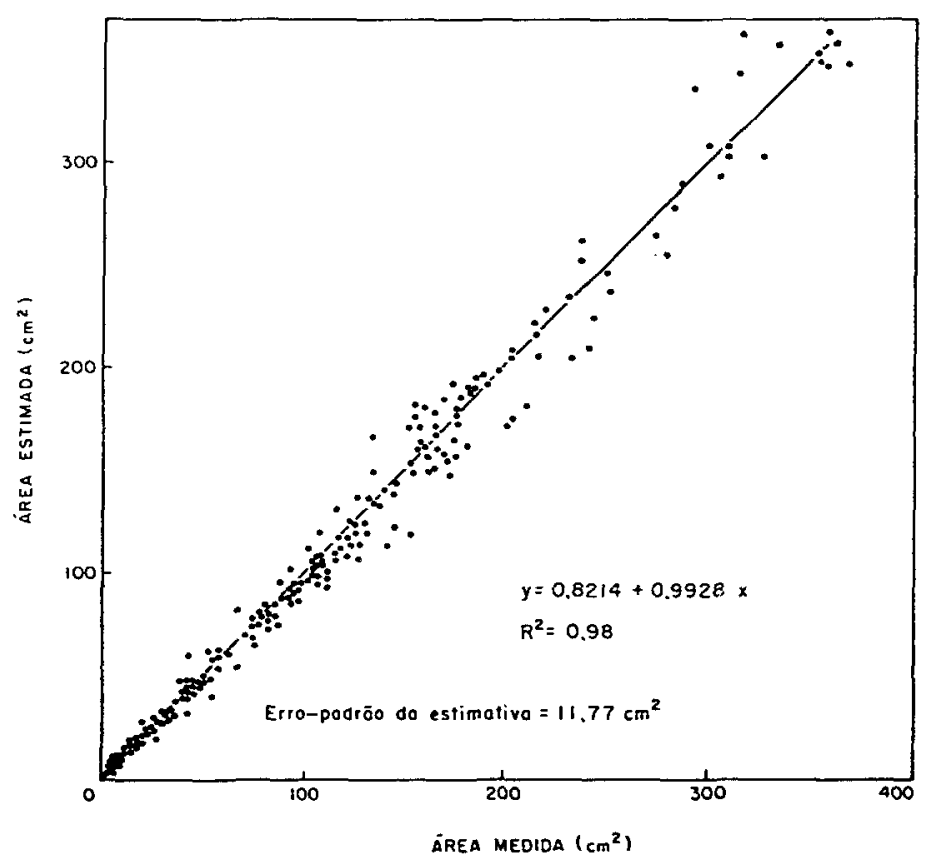

FIGURA 3. Comparação entre valores estimados e medidos de área foliar em videira, cv. Niagara Rosada

O coeficiente de deteminação $\left(R^{2}\right)$ foi 0,98 e, como se pode observar, os coeficientes linear $(0,82)$ e angular $(0,99)$ da reta aproximam-se de 0 e 1 , respectivamente, mostrando que as estimativas da área foliar da videira, através da área do círculo corrigida pelo fator 0,85 , são bastante confiáveis. $O$ erro-padrão da estimativa foi de $11,8 \mathrm{~cm}^{2}$.

Baseando nesses resultados, nota-se que a estimativa da área foliar da videira 'Niagara Rosada' pode ser feita através de simples determinaçōes da largura das folhas, técnica que, além de rápida, apresenta a característica de ser não destrutiva. 


\section{SUMMARY \\ RAPID ESTIMATION OF LEAF AREA IN GRAPE, CV. NIAGARA ROSADA}

Width of leaf blade was closely correlated with leaf area in leaves of grapes cv. Niagara Rosada. It was found that the shape of any leaf was similar to a circle. A short-cut procedure for estimating easily, rapidly and precisely the leaf area was developed. The equation relating leaf area (AF) to width of leaf blade (L) was: AF $=0.85 \pi(\mathrm{L} / 2)^{2}$.

Index terms: leaf area; grape.

\section{REFERÊNCIAS BIBLIOGRÁFICAS}

ARORA, J.S. \& CHANANA, Y.R. Measurement of leaf area in grapes. Punjab Horticultural Journal, 15(3/4):95-99, 1975.

CARBONEAU, A. Principes et méthodes de mesure de la surface foliaire. Essai de caractérisation des types de feuilles dans le genre Vitis. Annales de L'Amélioration des Plantes, 26(2):327-343, 1976.

KVET, J. \& MARSHALL, J.K. Assessment of leaf area and other assimilating plant surfaces. In: SESTAK, Z; CATZKY, J. \& JARVIS, P.G., ed. Plant photosynthetic production: manual of methods. The Hague, Junk, 1971. p.517-555.

MASHIJA, M.; SHARMA, B.B.; SINGH, R. \& SINGH, H.K. A note on rapid estimation of leaf area in grape. Progressive Horticulture, 11(4):45-48, 1980.

MANIVEL, L. \& WEAVER, R.J. Biometric correlations between leaf area and length measurements of "Grenache" grape leaves. Hortscience, 9(1):27-28, 1974. 